\title{
Ten Ways to Use a Relational Database at a Faculty Development Center
}

\author{
A. Jane Birch \\ Brigham Young University \\ Tara Gray \\ New Mexico State University
}

The authors thank Julene Bassett, Nancy Chism, Jean Conway, Jenith Larsen, Leslie Ortquist-Ahrens, Kathryn Plank, and Lynn Sorenson for their comments.

Providing quality support to faculty requires attention to administrative details and event logistics. As professiomals, we must also assess the impact of our work and be prepared to report to those who will judge its worth and allocate resources. To do this we need current, accurate data that are easy to access and easy to use. We also need a simple way to manage faculty development activities and evaluate the outcomes. The best technology for achieving these goals is a relational database. This chapter describes ten ways a relational database can be used to support faculty developers in their various roles and activities.

As faculty developers, our priority is serving faculty. Though we'd like to keep administrative details to a minimum, we cannot escape them altogether. If we are to serve faculty well, we must be 
organized. Faculty developers need current, accurate data that are easy to access and easy to use (Chism \& Szabó, 1996). This includes having a simple way to record our activities and assess the outcomes (Plank, Kalish, Rohdieck, \& Harper, 2005). It also includes reporting what we are doing to those who will judge its worth and allocate resources (Frantz, Beebe, Horvath, Canales, \& Swee, 2005). The best technology for achieving these goals is a relational database (a database that contains multiple tables of data that are related to each other). In this chapter we describe ten ways a relational database can be used to support the activities of a faculty development center.

Most faculty developers currently employ assorted low-tech tools to administer and assess faculty development programs (Chism, 2003). These tools may include file folders full of paper, text documents, spreadsheets, or even flat-file databases (simple databases in which all data are recorded in a single table). These tools are limited and inflexible and make generating reports very difficult. Their simplicity makes them suitable for small tasks, such as managing single events, but they are not sophisticated enough to efficiently manage a variety of events or services over a longer time span. Using these tools, one center reported that their program coordinator took eight weeks to complete their annual report (Plank et al., 2005).

Relational databases are substantially more powerful, flexible, and expandable than alternative methods of tracking data. For instance, relational databases virtually eliminate data replication because data (such as names, addresses, and dates) can be entered (or updated) once and become immediately accessible throughout the system. Without a relational database, the same data are inevitably entered multiple times, drastically increasing complexity, time needed for maintenance, and possibility for inconsistencies. In addition, because of the simple, efficient way in which data are organized in a relational database, the data can be used, reused, combined, searched, sorted, edited, displayed, and printed in a variety of ways that are difficult, if not impossible, to do with alternative methods of organization.

A well-designed database provides the power and flexibility to accomplish a wide variety of administrative tasks for any number of people and events over an unlimited time span. A good database can help faculty developers serve faculty better while 
significantly reducing the time needed to accomplish related administrative tasks (by our estimates, a 30 to 90 percent time saving, depending on the task). In this way, the database is a workhorse and is like having an extra staff member at the center (Eynon \& Chism, 2007). Although setting up such a database system is not easy (it may take several months of concerted effort), it is well worth the investment.

Brigham Young University (BYU) and New Mexico State University (NMSU) have created relational databases to serve the ongoing administrative and assessment needs of their centers. Both databases were created using FileMaker Pro-a powerful and user-friendly relational database program. FileMaker Pro is flexible enough to handle almost any conceivable data need in a faculty development center and can be used with both Macintosh and Windows operating systems. However, other relational database programs, such as Microsoft Access or MySQL, can be used. The ideas in this chapter apply to most relational database software applications on the market today.

The purpose of this chapter is to assist faculty developers in establishing or improving faculty development databases. Next are ten important ways a database can assist a faculty development center. It is not necessary for a database to do all of the following, so consider each item in light of current needs. The items are divided into record keeping and managing events:

\section{Record Keeping}

1. Record all useful data.

2. Quickly locate needed data.

3. Organize data for assessment, strategic planning, and reporting.

4. Increase accuracy and eliminate redundant data entry.

\section{Managing Events}

1. Track details needed to administer events.

2. Manage correspondence.

3. Enable participants to register online.

4. Create name tags and other customized materials.

5. Learn names by using photos.

6. Create a membership system. 


\section{Record Keeping}

Like a well-managed home, a well-managed office has a place for everything and everything in its place. A relational database provides a logical, efficient location to store all useful data; it also makes those data accessible to everyone at the center.

\section{Record All Useful Data}

Most centers record data about the clients whom they serve. A database can store information about the center's activities in order to better administer, report on, and archive events. At a minimum, the name of each program, an outline of the activities, the date, and the participants' names can be recorded. To track more data at BYU, we can include the learning objectives, a detailed description and evaluation of what happened, publicity used, media handouts, cost, innovations, and future plans. We can also track all the people involved in the activity, including participants, cosponsors, presenters, event administrators, student assistants, and people who were invited or who planned to attend but did not for one reason or another.

A relational database is an excellent system for recording data for activities with multiple concurrent participants (such as workshops), but most faculty development centers provide many other services and resources. A database can also assist with these. For example, a faculty development database can be used to do the following:

1. Record notes about each session with each client, along with follow-up notes on things to do and a method for tracking their completion.

2. Recall information about individual clients and their previous interactions with the center before they arrive at the office for a consultation.

3. Share resources used by staff members in working with clients.

4. Manage complex programs such as Students Consulting on Teaching (Sorenson, 2000), where student schedules must be matched with faculty schedules, equipment checked in and checked out, and reports managed. 
5. Keep records of how staff members use their time to better "measure, track, and report the work that centers do" (Plank et al., 2005, p. 174).

6. Record costs associated with each activity, along with evaluation data gathered.

7. Manage a large library collection to more easily locate resources and to facilitate a convenient check-out process with automatic e-mail reminders about due dates.

8. Keep records of one-time or recurring projects that do not include either clients or participants (for example, creating a database for the center).

The amount of data stored in a database depends on the resources and objectives of the center. The accompanying Web site (fc.byu.edu/jpages/database) contains an extensive list of the types of data that might be included in a faculty development database.

Entering data into a database can be done in a variety of ways. NMSU has clients enter contact information about themselves using online registration. BYU imports (or manually enters) a great deal more information, not just about clients but also about each unit on campus and each activity of the center. With the right permission and technical assistance, you can link your database directly into the institutional database, thereby enabling dynamic access to data housed by the university without having to enter it at all. To obtain data from the university, be prepared to demonstrate genuine need and provide convincing evidence that the data will be carefully safeguarded. (This process may take many months, so start early.)

It may take time to get the needed data into a database but, depending on your needs, it can be very useful to have all data in one place. For example, including demographic information about clients is invaluable for determining which populations are being served (Chism, 2003) and for targeting specific audiences (Holton, 2002). As a rule of thumb, we recommend entering all the data that will be useful for your purposes, but no more. Including excess data that no one uses increases the work needed to maintain the database and decreases the motivation to use it (Chism, 2003). 


\section{Quickly Locate Needed Data}

The central reason for storing data is to use them at a later date. Because a relational database can hold all of the data important to the center in one location, it eliminates most of the guesswork (not to mention frustration) of remembering where important data are stored. In addition, because of the highly efficient way a good relational database stores data, it is easy to access the data quickly through database searches or queries.

How much data are entered will determine the kind of searches that can be performed for data retrieval. For example, the BYU database can be used to locate "all professors promoted within the past 5 years." This search could not be done on the NMSU database because only current rank has been entered; the year that rank was obtained has not been entered. A Web site that supplements this chapter (fc.byu.edu/jpages/database) shows a representative listing of the kind of searches that can be done with a well-designed database. Consider carefully what questions you need answered before designing your database.

\section{Organize Data for Assessment, Strategic Planning, and Reporting}

A well-designed database system shines as a tool to document and analyze the work of a center and to assess and report on its impact (Plank et al., 2005). Data generated from the database create a useful portrait showing which faculty members are served, how they are served, and the cost of the service. The level of analysis can range from how the center serves the campus as a whole to any specific group of people or even to any individual. Data organized in a database can be used to evaluate which colleges or departments are underrepresented among participants, which services cost a lot in time or money but attract little use, and which services participants find most helpful. Having current, accurate data at your fingertips is invaluable for conducting internal reviews, cost-benefit analyses, budget requests, and strategic planning (Chism, 2003; Chism \& Szabó, 1996, 1997; Frantz et al., 2005; Mullinix, 2006; Plank et al., 2005).

Administrators also need an accurate picture of what the center is doing and the impact of its work (Frantz et al., 2005). By 
using a database, needed data are likely to be more accurate and comprehensive and take far less time to compile (Plank et al., 2005). Data in a database can be used to respond to appropriate requests for information from any level of administration, as well as in annual reports, budget proposals, and other reports. Data generated by the database provide a body of evidence that can be used by the center to document careful use of resources or to justify requests for further budget increases (Frantz et al.). This information can assist a center in "tooting its own horn"-a role most centers shun but one that may become important to the survival of some centers (Bartlett, 2002; Plank et al., 2005).

At NMSU, the center uses its database to raise money from the deans by showing them a report that documents the percentage of participation that comes from each college. These percentage stats are used to determine "fair share pledging" for each college. For example, if a college were using 10 percent of the center's resources in year one but 12 percent of the resources in year two, the college would be asked to pay 12 percent (rather than 10 percent) of the total donated that year by deans. Over time, this allows the amount that deans appropriately pay to increase as the costs to the center increase. NMSU now raises about $\$ 100,000$ from colleges and other units on campus (Gray \& Conway, 2007).

Plank and colleagues (2005) note that just as we remind faculty that "we can no longer (if we ever could) be excellent simply by assertion" (p. 186), so must faculty development centers provide evidence of the impact of their work. Shortly before the thirty-year-old teaching and learning center at the University of Nebraska was discontinued, the director of the center was told that she had "a week to write a report-not to exceed two pagesexplaining why [the center's] work was valuable to the university" (Bartlett, 2002, p. A10). Eventually, most centers may be held accountable for the resources that they use. If we postpone gathering concrete statistics until others demand them, it may be too late (or too difficult) to produce accurate data (Frantz et al., 2005). Data should be collected systematically as part of the natural workflow (Chism \& Szabó, 1996, 1997; Plank et al., 2005). By incorporating the use of a database into the everyday work of the center, data are kept up to date and readily accessible. 


\section{Increase Accuracy and Eliminate Redundant Data Entry}

As mentioned earlier, a relational database allows data to be entered just once to be instantly available to every authorized member of the center for any relevant project or activity. For example, once a client's name or department is entered, it is instantly available for an unlimited number of future uses: e-mails, letters, name tags, seating charts, gift certificates, reports, and so forth. Without a database, consider how many times the same information is typed (and proofread) over and over again.

Having accurate data is important, so it is critical to develop simple protocols for data entry and to train staff on the importance of accuracy (Chism, 2003). Modern database applications are designed to facilitate accuracy by providing users with simple data-entry methods, such as drop-down menus, rather than requiring them to type everything by hand. In addition, good database programs employ a variety of data-testing techniques that can be used to immediately identify and resolve common mistakes (for example, illogical dates, empty fields, and duplications).

\section{Managing Events}

There are a myriad of details involved in sponsoring successful faculty development events (Hilsen \& Wadsworth, 2002). A database proves indispensable in helping to manage these details. In addition to helping track RSVPs and attendance, the database can be used to organize participant groups, handouts, seating, food requests, survey data, and any idiosyncratic information needed for the specific purposes of an activity.

\section{Track Details Needed to Administer Events}

The BYU database helps to manage presentations by tracking all information needed to coordinate with the presenters for each specific event, including requests and responses, travel arrangements, media, handouts, equipment, introductions, and thankyou letters. The database is also used to help select appropriate presenters for future events by storing information about possible 
presenters, such as areas of expertise, past evaluation data, demographics, and contact information.

Relational databases facilitate other logistical tasks, such as quickly gathering lists of people to contact; printing programs, agendas, seating charts, attendance rolls, and participant directories; exporting or merging data; and handling all follow-up tasks, including gathering and storing evaluation data, sending follow-up memos, recording ideas for making the event better next time, noting expenses, and updating the inventory of materials that can be used in the future. A database is also particularly suited to drastically simplifying management of all correspondence to participants, presenters, and others (this function is described in detail next).

Beyond supporting logistical tasks, a database can be used as a project management tool. At BYU, the database stores structured "to-do lists" for some of the more complicated programs that the center administers. Each such program has a set of tasks with detailed notes about what needs to be done, who is responsible for doing it, and when it should be completed. Each task includes multiple subtasks with further details, which helps users to complete each item quickly and effectively. Once they are completed, tasks are checked off. Because everyone accesses the same data through the database, all members of the team see exactly what has been done and what still needs doing.

\section{Manage Correspondence}

At many faculty development centers the amount of communication among staff, participants, and clients can be enormous. Correspondence for workshops may include invitations, reminders to RSVP, confirmations of registration, reminders to attend, and requests for feedback. This type of correspondence is significantly simplified by using a database system. In fact, when properly set up, the database does all of this via e-mail, with minimal effort from staff members. By using a database, each piece of correspondence can be effortlessly customized for individual recipients. Beyond e-mail, the database assists in quickly producing customized letters, memos, faxes, envelopes, and labels.

Any text used in correspondence at BYU can be saved in the database and reused in the future. The next time the same or 
similar event occurs, quick modifications to the stored text are made, and the database is ready to e-mail or print the new set of correspondence. The database can also keep a record of exactly what correspondence has been sent to each individual, as well as any responses from that person.

\section{Enable Participants to Register Online}

Developing a database-driven online registration system requires extensive technical expertise and development time, but the payoff can be substantial. At NMSU, about 700 people register for an average of three or four workshops each, for a total of 2,672 unique registrations per year. In the past, participants registered by phone and e-mail. That's a lot of phone calls and e-mail messages! Now the database interfaces with a Web site, which allows participants to register online. Having participants register online is much easier and more accurate because participants input their own data. As an added benefit, participants can check their registration online or modify it, which saves additional phone calls and e-mail messages.

The database at the Office for Professional Development at Indiana University-Purdue University Indianapolis (IUPUI) allows for online registration and database-generated event confirmations. With their e-mail confirmation, participants receive an Outlook vCal file that they can use to automatically insert information about the upcoming event into their electronic calendars (N.V.N. Chism, personal communication, May 21, 2007). In addition to allowing participants to register online and be reminded of their registrations, Monmouth University takes online interface with a database a step further. They use online surveys to allow potential participants to indicate topics of workshops that they are interested in attending and to indicate when they are available to attend them. This allows the faculty developers to design workshops specifically targeted to the needs of participants, at times when the participants are available (Mullinix, 2006).

In addition to its uses for registration, a database can be used in conjunction with the Internet to provide other services. The IUPUI database allows faculty to apply online for grant proposals and awards, thus drastically reducing paperwork (J. S. Eynon, 
personal communication, May 23, 2007). There are also many elements of the extensive IUPUI Web site that are driven by their database, making the site easily changeable, dynamic, and tailored to individual user needs (Eynon \& Chism, 2007).

\section{Create Name Tags and Other Customized Materials}

Once participants are registered, it is easy to create databasegenerated participant name tags-a few mouse clicks will send them directly to the printer. Creating name tags (or name plates, if preferred) through a database is also more professional. Our name tags have the person's name and department, as well as the center logo, and can be printed in color. Databases also allow us to customize other materials for participants, including certificates, gift cards, thank-you notes, and binder labels.

\section{Learn Names by Using Photos}

Faculty developers know and appreciate the importance of teachers learning the names of their students (Auster \& MacRone, 1994). By adding photos to the database, faculty developers can easily memorize names, faces, and any needed information about the individuals served through their centers. At BYU, photos are displayed throughout the database, so users can easily associate names with faces whenever the database is accessed. Before each event, we can use the database to quickly generate electronic "flash cards," which help us to refresh our memories. In just a few minutes, we are prepared to greet most participants by name. The database is also used to print photo directories of any group of people for use away from the computer.

Getting photos for a database may or may not be easy. Most institutions take digital photos of all employees for I.D. or directory purposes. Using these photos may result in the best collection, but getting permission to use them can be difficult. One alternative is to download digital photos that appear on departmental Web sites. If nondigital photos are available, they may be scanned into the computer, or centers may purchase a digital camera and take the photos themselves (perhaps starting with the new faculty). Once you have the photos, importing them into the database is a relatively simple procedure. 


\section{Create a Membership System}

At NMSU, the task force that created the faculty development center indicated that they didn't mind participating in professional development but they wanted credit for it. The center responded by creating a membership system. Memberships are earned by participation in the center activities and awarded on a yearly basis. The database is used to track which participants have earned membership in the center: a basic membership (ten hours or more of participation), a sustaining membership (twenty hours or more of participation), or a distinguished membership (forty hours or more of participation).

The membership system allows the center to offer various kinds of recognition and awards for various levels of membership. The system has created quite a bit of interest. At the end of each year, over two hundred members are honored. The database enables each member to receive a report documenting his or her participation at all center events, along with encouragement to use the information to strengthen vitae and annual reports. Similar reports are sent to each department head and dean (Gray \& Conway, 2007). Individual faculty members often request a printed list of all activities in which they have participated during the current year (which is available to them online) and past years (which must be printed for them).

\section{Overcome Challenges}

The design, development, and maintenance of a relational database of the scope described here is not a small project. We estimate that the time to develop a comprehensive system (especially one linked to a dynamic Web site) requires approximately two to six months of full-time work if starting from scratch (depending on the skill level of the developer). Not every faculty development center has the resources or desire to create such a comprehensive system, but developing a system narrower in scope can drastically cut the development time. In fact, a simple database with just client contact information could be designed and up and running within a few hours! If time and resources are tight, consider designing a simple database that focuses on just a 
few of the functions that are highest priority; later, the database can be expanded to include additional functionality.

When it becomes possible to create a more comprehensive, robust database system, consider working with a professional database designer. Unless a center is lucky enough to employ someone with excellent technical skills, most faculty developers probably will not want to build a database totally in-house (note that this is not an acceptable project to assign to a temporary student worker). Fortunately, it is not difficult to find competent professionals with the necessary technical expertise, and joining forces with a similar center is a good way to get the job done. The California State University system developed a faculty development center management tool (named Depot) to be used systemwide on twenty-three campuses (C. Desrochers, personal communication, July 25, 2007).

There are several other ways to reduce database development time. One option is to build on the success of teaching centers that have successfully implemented comprehensive database systems. Such centers may be willing to share design elements, including screen shots of their databases and Web interfaces. The Ohio State University faculty development center generously provides a CD with information about their database and others modeled on it. BYU has developed a Web site with detailed information about the design of their database system (fc.byu.edu/jpages/database). Using such detailed information as a blueprint could cut development time by as much as 25 to 50 percent.

Still another route is to adopt a database developed at another center. The databases at NMSU and BYU are available (with restrictions) for other centers to use. Remember, however, that a database should be customized to a particular center's needs, so another center's database must be modified to fit a new center. When adopting a database, adequate time and money must be budgeted for learning how to use it and tailoring it to particular needs. Keep in mind that this additional investment is not insignificant.

In whatever way a database system is designed and developed, actively involve everyone who will ultimately use it (Plank et al., 2005). This includes discussing the purpose of the database and 
how it will support the mission of the center, needed functions and reports, and the design of the user interface. None of these important elements should be left to the discretion of the database developer! Involving the entire staff will result in a much more functional, user-friendly database that better meets their needs. It will also build support and excitement for making the transition to new ways of doing things.

A necessary precaution when using databases is to back up data regularly. This is true of all data stored on hard drives, but it is particularly true of data that are accessed and changed frequently and on which the entire staff depends for daily operations. At BYU, the database is backed up automatically every hour. Once a week, the entire database is burned to a CD and stored off campus.

Finally, in designing the database, carefully consider the need to respect the confidentiality of the data collected (Chism, 2003). Strict policies and protocols should be planned in advance to make sure that staff is well trained and that the data are secure. Good relational database software will include multiple ways to protect data and provide multiple layers of access so that sensitive data are available only to those who need it.

\section{Conclusion}

The primary job of a faculty developer is not administering and assessing programs; the primary job is supporting faculty. Nevertheless, the effective faculty developer must do all three. Because a well-designed database system helps a faculty developer be far more effective and efficient in administering and assessing programs, more time and energy can be devoted to helping faculty. The service provided can also be at a higher level of quality and professionalism. Affordable tools needed to develop a comprehensive, user-friendly database system were not readily available even ten years ago. Now, relatively powerful, inexpensive relational databases can enable every faculty developer to handle administrative tasks with the minimum of time and effort-and possibly even to enjoy these aspects of the job! 


\section{References}

Auster, C. J., \& MacRone, M. (1994). The classroom as a negotiated social setting: An empirical study of the effects of faculty members' behavior on students' participation. Teaching Sociology, 22, 289-300.

Bartlett, T. (2002, March 22). The unkindest cut. The Chronicle of Higher Education, p. A10.

Chism, N. V. N. (2003). How professional development units keep track of their services (based on responses to an e-mail inquiry on the POD listserv, December 30, 2002). Unpublished manuscript, Indiana UniversityPurdue University Indianapolis.

Chism, N. V. N., \& Szabó, B. (1996). Who uses faculty development services? In L. Richlin (Ed.), To improve the academy: Vol. 15. Resources for student, faculty, and institutional development (pp. 115-128). Stillwater, OK: New Forums Press.

Chism, N. V. N., \& Szabó, B. (1997-98). How faculty development programs evaluate their services. Jourmal of Staff, Program, and Organization Development, 15(2), 55-62.

Eynon, J., \& Chism, N. V. N. (2007, October). Tracking purpose and priorities: Database systems for monitoring our work. Paper presented at the 32nd annual meeting of the Professional and Organizational Development Network in Higher Education, Pittsburgh, PA.

Frantz, A. C., Beebe, S. A., Horvath, V. S., Canales, J., \& Swee, D. E. (2005). The roles of teaching and learning centers. In S. ChadwickBlossey \& D. R. Robertson (Eds.), To improve the academy: Vol. 23. Resources for faculty, instructional, and organizational development (pp. 72-90). Bolton, MA: Anker.

Gray, T., \& Conway, E. (2007). Build it [right] and they will come: Boosting attendance at your teaching center by building community. Journal of Faculty Development, 12(3), 179-184.

Hilsen, L. R., \& Wadsworth, E. C. (2002). Staging successful workshops. In K. H. Gillespie (Ed.), A guide to faculty development: Practical advice, examples, and resources (pp. 108-122). Bolton, MA: Anker.

Holton, S. A. (2002). Promoting your professional development program. In K. H. Gillespie (Ed.), A guide to faculty development: Practical advice, examples, and resources (pp. 100-107). Bolton, MA: Anker.

Mullinix, B. B. (2006). Building it for them: Faculty-centered program development and eManagement. In S. Chadwick-Blossey \& D. R. Robertson (Eds.), To improve the academy: Vol. 24. Resources for faculty, instructional, and organizational development (pp. 183-200). Bolton, MA: Anker. 
Plank, K, Kalish, A., Rohdieck, S., \& Harper, K. (2005). A vision beyond measurement: Creating an integrated data system for teaching centers. In S. Chadwick-Blossey \& D. R. Robertson (Eds.), To improve the academy: Vol. 23. Resources for faculty, instructional, and organizational development (pp. 173-190). Bolton, MA: Anker.

Sorenson, D. L. (2000). Student collaboration in faculty development: Connecting directly to the learning revolution. In E. C. Wadsworth (Ed.), To improve the academy: Vol. 8. Resources for student, faculty, and institutional development (pp. 97-121). Stillwater, OK: New Forums Press. 